\title{
Construction and Reform of "Core Courses of Electrical Major" Based on Information Technology
}

\author{
Huida Duan ${ }^{1 *}$ Xu Zhao ${ }^{2}$ \\ 1,2 School of Electrical and Information Engineering, Changchun Institute of Technology, Changchun, China \\ "Corresponding author.Email: Huida_duan@163.com
}

\begin{abstract}
The paper studied the multi-field application of modern information technology in course construction. Including teaching resource construction, online and outline blended teaching method reform, virtual simulation technology, reform of diversified teaching evaluation system and so on. The application of information technology has switched the traditional classroom teaching process. The combination of information technology and traditional classroom has realized complementary advantages and effectively promoted the improvement of teaching quality. The research shows the scientific use of information technology has become the inevitable trend of higher education development.
\end{abstract}

Keywords: Information technology, Blended teaching method, Course reform, Course construction.

\section{INTRODUCTION}

Since the beginning of the 21 st century, online education projects have developed rapidly under the impetus of information technology, which has promoted the continuous innovation of educational ideas and concepts [1]. The application of multimedia technology and internet technology has gradually changed the teaching model [2]. These technologies are no longer simple tools for teachers to display teaching content, but become one of the core elements to promote the reform of teaching and learning methods, the innovation of learning effect evaluation methods and the promotion of education quality [3-4]. The electrical engineering and automation major of our university is a national firstclass major construction point, and has passed the engineering education certification of the Ministry of Education in 2018. In recent years, adhering to the engineering education concept of "student-centered, output-oriented and continuous improvement", we attach importance to the connotation construction of core courses of electrical major. Relying on information technology, we constantly improve the construction of courses and teaching reform, and have achieved remarkable teaching achievements, which strongly support the quality of specialty construction and talent cultivation.

\section{CONSTRUCTION OF THREE- DIMENSIONAL HIGH-QUALITY ONLINE TEACHING RESOURCES}

According to the applied talent training position of the school and geared to the needs of training applied talents of the electric power industry, we clarified the course goal of each core courses of the major. Power industry personnel training requirements include: professional quality, innovation ability, international vision and social responsibility, competent for power system design, installation and commissioning, operation and maintenance, overhaul and test, information processing, engineering management and others.

In order to realize the outstanding goal of training the engineering application ability of solving complex problems, a course system with equal emphasis on theory and practice was constructed. The construction of information course teaching resources covers theoretical teaching, course design, course experiment and practice, etc.

\subsection{On-line Teaching Resources Construction of Theory Teaching}

Relying on "Rain Classroom" and "Super Star FanYa" information online education platform, we have 
completed the construction of high-quality online teaching resources for core courses. Specifically, it includes: theoretical teaching videos divided according to knowledge points, teaching multimedia courseware, question bank, course experiment projects, learning materials, practical teaching video and practical teaching guide etc.

In addition, in order to meet the "high-level, innovative, and challenging" course construction requirements proposed by the Ministry of Education of China, relevant teaching units have been set up. Students can improve their knowledge levels through out-of-class learning, and better meet the needs of stepped teaching. In order to comprehensively implement the educational guidelines formulated by the ministry of education of China "Morality Education", the construction of teaching resources also pays attention to the ideological and political education of students. The "ideological and political education" module is added to promote teachers and students pay attention to moral education in course construction.

\subsection{On-line Teaching Resources Construction of Practical Teaching}

The requirements for practical teaching in the core courses of the electrical major are relatively high. The students' engineering practice ability can be improved only through a lot of practical teaching activities. This requires good experimental conditions and advanced experimental equipments. This requires perfect experimental conditions and advanced experimental equipment which needing much investment. In order to better meet the requirements of practical teaching, "virtual simulation experiment technology" is introduced into each course, and a practical teaching resource system "Combination of virtual and actual teaching resource system" is built.

For example, the "Power System Analysis" course uses simulation software to complete power flow calculations, short-circuit current calculations, and system stability analysis. The "Relay Protection Principles" course uses virtual relay protection testing techniques to complete various fault analysis and protection design such as setting and parameter debugging, testing and so on.

Figure 1 is an example of virtual simulation analysis for "Power System Analysis".

Figure 2 is an example of virtual simulation analysis for "Relay Protection Principles".

In addition, with the help of modern virtual simulation technology, professional teachers completed the construction of practical course network teaching resources through independent development and introduction. They completed 2 provincial-level virtual simulation practical teaching projects such as "DC electric field air gap discharge virtual simulation experiment". The laboratory introduced virtual simulation practice platforms such as $500 \mathrm{kV}$ substations, wind farms, thermal power plants, power system dispatching automation system, etc. The threedimensional high-quality teaching construction provides a strong hardware guarantee for the realization of the professional core courses teaching goals.

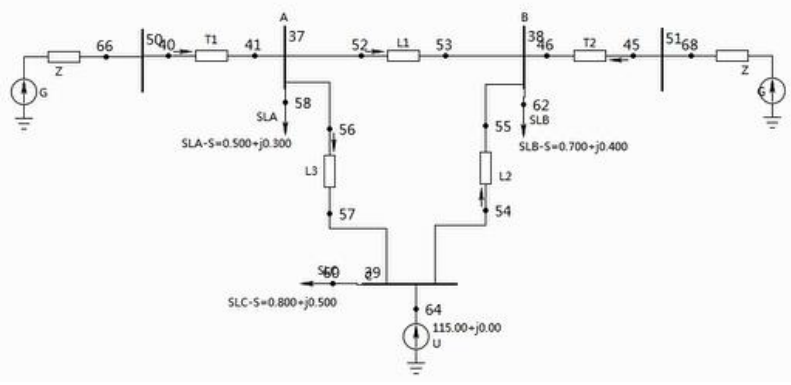

\begin{tabular}{l|l|l|l}
$G 1$ & $0.0000-j 1.68477$ & $0.0000-j 1.40160$ & $0.0000-j 0.00000$ \\
G2 & $0.0000-j 1.68477$ & $0.0000-j 1.40160$ & $0.0000-j 0.00000$ \\
\hline $3 B-2$ & $0.0000-j 0.00554$ & $0.0000+j 0.00469$ & $0.0000-j 0.00416$ \\
\hline $1 B-2$ & $0.0000-j 0.16082$ & $0.0000-j 0.13379$ & $0.0000+j 0.80579$ \\
\hline B- 2 & $0.0000-j 0.16082$ & $0.0000-j 0.13379$ & $0.0000-j 0.03413$ \\
\hline $5 B-2$ & $0.0000-j 0.00414$ & $0.0000+j 0.00350$ & $0.0000-j 0.03413$ \\
$6 B-2$ & $0.0000-j 0.00414$ & $0.0000+j 0.00350$ & $0.0000+j 0.35027$ \\
\hline $4 B-2$ & $0.0000-j 0.00554$ & $0.0000+j 0.00469$ & $0.0000+j 0.80579$ \\
$L 3=28 \mathrm{~km}$ & $0.0000+j 0.01249$ & $0.0000-j 0.01056$ & $0.0000-j 0.00111$ \\
\hline $\mathrm{L} 2=25 \mathrm{~km}$ & $0.0000+j 0.01328$ & $0.0000-j 0.01123$ & $0.0000-j 0.06798$ \\
$\mathrm{~L} 1=18 \mathrm{~km}$ & $0.0000+j 0.32164$ & $0.0000-j 0.26758$ & $0.0000-j 0.06826$ \\
$\mathrm{~L} 4=15 \mathrm{~km}$ & $0.0000+j 0.01495$ & $0.0000-j 0.01265$ & $0.0000-j 0.00229$
\end{tabular}

Figure 1 Example of virtual simulation analysis for "Power System Analysis"

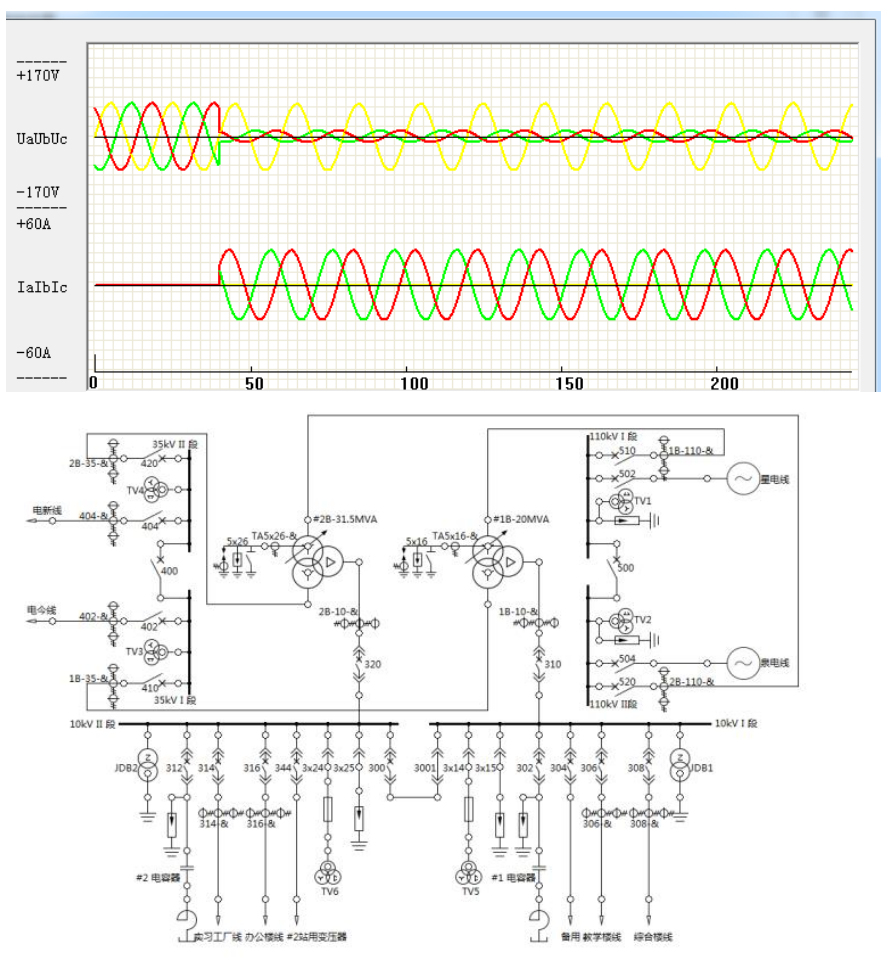

Figure 2 Example of virtual simulation analysis for "Relay Protection Principles" 


\section{TEACHING METHOD REFORM BASED ON INFORMATION TECHNOLOGY}

The reform of course teaching methods is the core index of course construction. Diversified teaching methods can effectively improve the teaching effect. The difficulty of teaching method reform is to take students as the center and make full use of information technology. In the core courses of electrical mayor, teachers prepare lessons from the perspective of students and implement teaching with the method of online and outline Blended teaching [5], so as to strengthen the online and outline interaction between teachers and students.

In the teaching process, network teaching resources and modern information technology are fully used to embody personalized teaching.

Before class, through the analysis of the course teaching objectives, formulate the requirements of the pre-class teaching objectives, teaching content analysis, assessment and evaluation design of each course, and assign the task to the students, so that they can clarify the teaching requirements and assessment methods.

In teaching activities, Blended teaching methods are adopted, including classroom teaching, case teaching, discussion, questioning and interaction between teachers and students.

After class teaching, teachers can assign after-class learning tasks for students through exercises, group discussion and so on. After completing the tasks, students upload their homework results to the online teaching system. Teachers can master students' learning status through students' learning feedback materials and give targeted guidance. In this way, the learning effect can be improved effectively and the initiative of students' learning can be aroused. Students can finish the corresponding work according to their own ability, and realize the teaching in different levels.

The whole teaching activity was carried out in accordance with bloom's cognitive model as shown in Figure 3, which was progressive and interlocking.

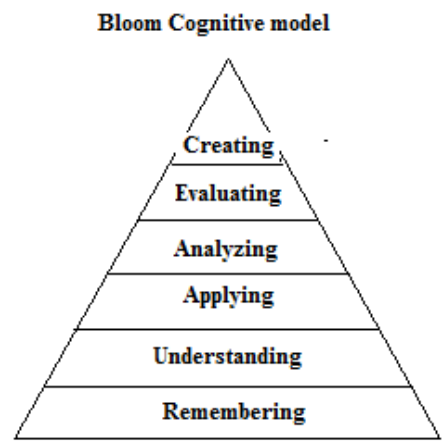

Figure 3 Bloom's cognitive model
Through Blended teaching method, network learning and traditional classroom learning are combined to achieve complementary advantages. It can not only optimize the integration of learning resources, but also improve the learning effect. It can not only play the leading role of teachers in classroom learning, but also play the main role of "student-centered". It is beneficial for teachers and students to exchange and interact with each other in their spare time. This Blended teaching method makes up for the lack of teaching hours face-toface in classroom.

\section{REFORM OF DIVERSIFIED COURSE EVALUATION METHODS}

Information technology not only brings the reform of course teaching resources and teaching methods, but also promotes the reform of diversified teaching evaluation methods. In the construction of major core courses, in order to more scientifically reflect the cultivation effect of students' "knowledge, ability and quality", we pay more attention to diversification and process in the evaluation system. Through the reform of these assessment methods, students' autonomy in learning can be fully regulated.

In the past, the evaluation of students only paid attention to the simple summative evaluation, and the evaluation of the learning process was often lack of pertinence, single evaluation method, and lack of supervision, regulation and incentive to the learning process. The diversified assessment methods supported by information technology are more conducive to the indepth development of process assessment and evaluation. The assessment method is a combination of process assessment and final assessment. Process assessment includes specific indicators such as pre-class, in-class and after-class performance, online and offline discussions, chapter tests, project design, reports and so on. Teachers can take students' online learning activities and process as an important indicator of assessment, and use the data of online teaching platform to find problems in students' learning in time. Teachers can give warning and guidance to students according to the problems found, and urge the students to make full use of highquality teaching resources for independent learning and improve their interest in course learning. The final exam consists of the final paper and a summary report of the course.

\section{CORE COURSES CONSTRUCTION EFFECT}

Through several years of construction, the core courses of electrical mayor have basically completed the course construction and reform based on information technology, and achieved a series of course construction achievements. 
Among the major core courses:

"Power System Analysis" was rated as the first-class course by Jilin Provincial Education Department.

"Circuit Theory", "Electrical Machinery" and "Power System Relay Protection" were rated as provincial quality online courses by Jilin Provincial Education Department.

"High Voltage Technology", "Power Plant Electrical System" and "Power Electronics Technology" were rated as school-level Blended teaching golden course.

In 2020, the major of Electrical Engineering and Automation was rated as the national first-class major by the Ministry of Education

\section{CONCLUSIONS}

The rapid development of information technology constantly promotes the deepening of education and teaching reform, which is not only in terms of education idea, but also in terms of teaching content, teaching method and teaching effective evaluation.

The construction of high - level first-class courses is inseparable from the scientific and rational application of information technology. Based on the experience of core courses construction of electrical engineering and automation major in our school, this paper summarizes the new methods and new ideas of course construction brought by information technology.

At the same time, this paper also shares some of the results achieved in the course teaching reform. These reforms and attempts have been recognized by students.

"Taking undergraduate education as the foundation" is the basic requirement of higher education teaching proposed by the Ministry of Education. The course teaching brought by information technology needs teachers to pay more time and energy, but also needs students to give more active cooperation.

To sum up, the reform of course construction brought by information technology is worth further study step by step.

\section{ACKNOWLEDGMENTS}

This paper is supported by Fund Project: key research topic of Higher Education Teaching Reform in Jilin Province in 2020 (Reform and Practice of deep Integration of information technology and traditional Classroom)

Fund Project: Jilin Provincial Department of Education industry and education cooperation. (The course reform and practice of Power System Relay Protection under the cultivation mode of applied talents).

\section{REFERENCES}

[1] Y Wu. Building Chinese Golden Course. University Education in China [J]. pp. 4-9, December 2018. (In Chinese)

[2] Tiantian Wang, Xiaohong Su, Peijun Ma, Yuying Wang, Kuanquan Wang. Ability-training-oriented automated assessment in introductory programming course $[\mathrm{J}]$. Computers \& Education , vol:56, pp.220-226, January 2011. (In Chinese)

[3] Tayeb Brahimi, Akila Sarirete. Learning outside the classroom through MOOCs $[\mathrm{J}]$.Computers in Human Behavio. 2015

[4] Christopher L. Thomas, Gary M. Pavlechko, Jerrell C. Cassady. An examination of the mediating role of learning space design on the relation between instructor effectiveness and student engagement [J]. Learning Environments Research. 2019 (1)

[5] W Wendy. Porter Charles R. Graham Kristian. Blended learning in higher education: Institutional adoption and implementation . Computers \& Education [J]. 2014.

[6] Felicity Small, David Dowell, Peter Simmons. Teacher communication preferred over peer interaction: Student satisfaction with different tools in a virtual learning environment [J]. Journal of International Education in Business. 2012 (2).

[7] Sun Yahong. The Research of Data Structure Teaching Based on Computational Thinking [A]. Proceedings of 2019 3rd International Conference on Economics, Management Engineering and Education Technology (ICEMEET 2019) .2019. 